OPEN ACCESS

Edited by:

Peter Bede,

Trinity College Dublin, Ireland

Reviewed by:

Pierre-francois Pradat,

Hôpitaux Universitaires Pitié

Salpêtrière, France

Yana Yunusova,

University of Toronto, Canada

Foteini Christidi,

National and Kapodistrian University

of Athens Medical School, Greece

*Correspondence:

Eneida Mioshi

e.mioshi@uea.ac.uk

Specialty section:

This article was submitted to

Neurodegeneration,

a section of the journal

Frontiers in Neurology

Received: 25 November 2018

Accepted: 14 February 2019

Published: 11 March 2019

Citation:

Caga J, Hsieh S, Lillo P, Dudley K and Mioshi E (2019) The Impact of

Cognitive and Behavioral Symptoms on ALS Patients and Their Caregivers.

Front. Neurol. 10:192.

doi: 10.3389/fneur.2019.00192

\section{The Impact of Cognitive and Behavioral Symptoms on ALS Patients and Their Caregivers}

\author{
Jashelle Caga ${ }^{1,2}$, Sharpley Hsieh ${ }^{3}$, Patricia Lillo ${ }^{4}$, Kaitlin Dudley ${ }^{5}$ and Eneida Mioshi ${ }^{5 *}$ \\ ${ }^{1}$ Sydney Medical School, University of Sydney, Camperdown, NSW, Australia, ${ }^{2}$ Brain \& Mind Centre, University of Sydney, \\ Camperdown, NSW, Australia, ${ }^{3}$ Faculty of Health and Behavioural Sciences, School of Psychology, University of \\ Queensland, QLD, Australia, ${ }^{4}$ Departamento de Neurología Sur/Neurociencia, Facultad de Medicina, Universidad de Chile \& \\ Geroscience Center for Brain Health and Metabolism, Santiago, Chile, ${ }^{5}$ School of Health Sciences, University of East Anglia, \\ Norwich, United Kingdom
}

Previously thought to be a pure motor disease, amyotrophic lateral sclerosis (ALS) is now established as multisystem neurodegenerative disorder that lies on a continuum with frontotemporal dementia (FTD). Cognitive and behavioral symptoms primarily extend to executive function, personality, social conduct, and emotion processing. The assessment and management of cognitive and behavioral symptoms is complicated as they must be differentiated from psychological responses to a terminal diagnosis and progressive physical impairment. This is made more difficult by the limited number of studies investigating how these symptoms specifically affect patients and caregivers well-being. The current review focuses on the impact of cognitive and behavioral symptoms on patient and caregiver well-being and their implications for future research and interventions in ALS. This is an important area of research that could form the basis for more tailored, and potentially more successful, non-pharmacological interventions to improve psychological well-being among patients with ALS and their caregivers.

Keywords: amyotrophic lateral sclerosis, dementia, depression, quality of life, caregiver, burden, adherence, non-pharmacological interventions

\section{BACKGROUND}

Amyotrophic lateral sclerosis (ALS) is a multisystem neurodegenerative disorder which includes a broad spectrum of non-motor symptoms that can dominate the clinical presentation $(1,2)$. Cognitive and behavioral symptoms include impaired executive function, deficits in social and emotional cognition, apathy, disinhibition, and perseveration similar to that seen in frontotemporal dementia (FTD). Frontotemporal dysfunction of varying severity can affect more than $50 \%$ of ALS patients (3), with $\sim 8-14 \%$ meeting full diagnostic criteria for FTD (4-8). As such, early detection and timely management of cognitive and behavioral symptoms is widely acknowledged as an important aspect of contemporary ALS care (9). However, fully assessing cognitive and behavioral symptoms in ALS is made difficult by the fact that these symptoms must be distinguished from psychological reactions to a terminal diagnosis and the progressive physical loss that comes alongside it. Our narrative review focuses on evaluating the impact of cognitive and behavioral symptoms on patient and caregiver well-being and their implications for developing future non-pharmacological interventions in ALS. Gathering this research can help form more appropriate and effective non-pharmacological interventions to improve psychological well-being among patients with ALS and their caregivers. 


\section{SEARCH STRATEGY AND SELECTION CRITERIA}

For this narrative review references were primarily searched through PubMed. The following terms were systematically searched: "amyotrophic lateral sclerosis"; "motor neuron(e) disease"; "cognitive"; "behavioral"; "depression"; "anxiety"; "quality of life"; "psychological health"; "caregiver"; "carer"; "burden"; "strain"; "stress"; "compliance"; "adherence"; "psychosocial intervention"; "non-pharmacological intervention"; "support"; "manage"; "intervention"; "care"; "caring"; "coping"; "cope"; "frontotemporal dementia." The section on non-pharmacological interventions for cognitive and behavioral symptoms in ALS also used the MEDLINE, EMBASE, PsycINFO, AMED, and CINAHL databases. Searches included papers published in English between May/2013 and July/2018. Research articles relevant to ALS and FTD were included in the review.

\section{PSYCHOLOGICAL SYMPTOMS IN ALS}

The psychological impact of ALS has been widely addressed in the literature. Anxiety and depression, particularly depression are often used as clinical markers of psychological morbidity in patients diagnosed with ALS. Self-report measures, particularly the Hospital Anxiety and Depression Scale and Beck's Depression Inventory remain the most widely used measures. Based on the Structured Clinical Interview for the Diagnostic and Statistical Manual of Mental Disorders, the "gold standard" for assessment of depression, the rate of clinical depression ranges between 9 and $12 \%$ in ALS $(10,11)$. Perhaps not surprisingly, selfreport measures of depression tend to show more variable rates of depression ranging from 20 to $64 \%$ (12-20). Similarly, the prevalence rates of anxiety vary widely, with rates ranging as low as $8 \%$ to as high as $88 \%$ among patients with ALS $(12,14,18$, $19,21)$. The severity of symptoms appear to be predominantly in the mild range. Despite the low rates of clinical depression and anxiety, patients with ALS have been shown to be at increased risk of being diagnosed with depression, anxiety and other neurotic or stress-related disorders following diagnosis (21-25), however this may be attributable to the clinicopathological overlap between ALS and FTD (24).

Management of psychological symptoms is crucial to maintaining quality of life. ALS patients provided with an assistive communication device in the early stages of the disease have been found to experience higher quality of life, particularly in the domains related to psychological and existential wellbeing (26). Quality of life and depression appear to be largely unrelated to patients' desire for hastened death (27) and endof-life choices (28). This may be due to satisfactory levels of quality of life typically reported by ALS patients $(29,30)$. In fact, several studies have shown that caregivers and healthy controls tend to underestimate ALS patients quality of life and psychological well-being (31), possibly reflecting a "disability paradox" (32). However, it should be noted that many quality of life measurements used were not ALS specific.

\section{THE IMPACT OF COGNITIVE AND BEHAVIORAL SYMPTOMS ON ALS PATIENT'S PSYCHOLOGICAL WELL-BEING}

To date, there is a paucity of research specifically examining cognitive/behavioral symptoms and patients' psychological well-being. The majority of recent studies on patients' psychological well-being have either excluded patients with cognitive/behavioral symptoms or have not specifically discussed findings in relation to cognitive/behavioral symptoms. This is an important area for future research given emerging findings showing a relationship between depression and cognitive/behavioral changes. Higher levels of depression have been associated with lower cognitive performance on the Edinburgh Cognitive and Behavioral ALS Screen (17), specifically the subtests measuring social cognitive deficits and inhibitory control (12). Findings regarding anxiety and cognitive function are inconsistent, with one recent study finding no relationship (12) and another showing a weak association between anxiety and cognitive performance, perhaps reflecting underlying behavioral changes, namely disinhibition (17). Indeed, the findings available on behavioral and psychological symptoms appear to be more consistent. A large scale study of cognitive and behavioral impairment, and depression showed that patients with behavioral impairment exhibited higher levels of depression and hopelessness (10). This may partly reflect the overlap between depression and behavioral symptoms, namely apathy $(33,34)$.

\section{THE IMPACT OF COGNITIVE AND BEHAVIORAL SYMPTOMS ON TREATMENT ADHERENCE IN ALS}

Adherence to treatment recommendations in ALS can extend survival (e.g., non-invasive ventilation or Riluzole), improve patients' quality of life $(35,36)$, and likely to reduce caregiver burden. Review articles of cognition and behavioral symptoms in ALS discuss the likely impact of these symptoms on treatment adherence (37-40), however only one study to date has investigated the effect of non-motor symptoms on treatment adherence in ALS (41). Non-adherence to non-invasive positivepressure ventilation and percutaneous endoscopic gastrostomy recommendations was 75 and $72 \%$ respectively for patients with ALS-FTD compared to 38 and $31 \%$ those with "motor only" symptoms. Therefore, the presence of a frontotemporal syndrome reduced adherence by half in ALS.

In general, ALS patients are compliant with recommendations made in multidisciplinary clinics (36). Out of a total of 287 recommendations made to 25 patients with ALS, patients complied fully with $59 \%$ of the recommendations made by the team. Not surprisingly, recommendations were greatest for physical needs (e.g., medications for symptoms such as spasm, saliva, sleep difficulties and interventions for nutrition and speech) and adherence was also highest for this category of recommendations. Interestingly, while patients with marked 
cognitive impairment were excluded in this study, patients with milder cognitive and behavioral symptoms (e.g., executive dysfunction) were included and may help explain why less than half of all recommendations were recalled (40\%) and only a small proportion of patients (32\%) had retained the written list of recommendations provided after the clinic visit. In total, $<5 \%$ of the total recommendations were for mental health needs of patients (e.g., anti-depressants) and almost no recommendations ( $<2 \%$ of total recommendations) were made for caregivers (e.g., increase caregiver hours, ALS respite care program, and caregiver training to aid in patient transport).

In general, studies of treatment adherence in ALS have not typically characterized non-motor symptoms in patient cohorts [e.g., physiotherapy exercises (42); respiratory support (43); tolerability of oral vs. tablet Riluzole (44); tolerability of early non-invasive ventilation use (45)] and is an exclusionary criteria in some studies [e.g., aerobic exercise therapy vs. cognitive behavioral therapy (46)]. It is therefore not surprising that motor predictors of treatment adherence are often reported. For example, symptomatic orthopnoea and dyspnoea, nocturnal hypoventilation, and spinal onset of symptoms have been associated with adherence to non-invasive ventilation (47-50). Functional scores (forced volume vital capacity and the revised ALS Functional Rating Scale) have also been identified as independent predictors of adherence to clinical trials and fewer protocol deviations (51).

\section{CAREGIVER BURDEN IN ALS}

Several studies have shown that caregiving in ALS affects caregivers' level of distress and quality of life (52). The psychological symptoms experienced by caregivers have a significant impact on caregiver burden (53). Burke et al. (54) demonstrated that caregiver distress explained 39\% of the variance in caregiver burden (54). In another study where caregivers were dichotomized into low and high burden groups, there were no differences across groups with respect to motor function (revised ALS Functional Rating Scale), bulbar/spinal onset, or survival time. Significant differences were only found when high and low-burden caregivers were compared on levels of anxiety, depression, distress and quality of life (55). A longitudinal study involving ALS patients with relatively preserved cognition demonstrated that anxiety and depression in caregivers were the best long-term predictors of burden (56).

An interesting study using a mixed methods approach (quantitative and qualitative) to assess burden in 81 informal ALS caregivers, showed that increased psychological distress, hours of care provided, and lower quality of life were the best predictors of caregiver burden, explaining $53 \%$ of variance. These caregivers identified difficulties related to four main themes: (a) the caregiving role and tasks associated with management of the condition, (b) psychosocial and emotional impact, (c) limitated time and restricted social life, and (d) significant impact in relationships with others and also identity (the process of "becoming" and "being" a caregiver) (57). Longitudinal studies have also demonstrated that disease severity causes strain and burden in caregivers over time $(58,59)$.

\section{THE IMPACT OF COGNITIVE AND BEHAVIORAL SYMPTOMS ON CAREGIVER BURDEN}

Recent evidence has demonstrated that both cognitive and behavioral symptoms contribute to caregiver burden in ALS (54, 60). A study involving 33 ALS patient-caregiver dyads showed that caregiver burden (Zarit Scale) was associated with executive dysfunction and behavioral changes, such as apathy and disinhibition (54). Similarly, findings from a Chinese study revealed that the degree of frontal dysfunction and behavioral changes (predominantly disinhibition) was significantly associated with caregiver burden (60).

More severe cognitive deficits have also been shown to predict caregiver burden in ALS (61). Conversely, a study involving 84 ALS patient-caregiver dyads found no correlation between caregiver burden (Caregiver Burden Inventory) and cognitive functioning (ALS-Cognitive Behavioral Screen). Only disease progression and behavioral symptoms were correlated with caregiver burden (62). Indeed, the level of burden for caregivers of ALS-FTD patients appears to increase with disease progression compared to a persistently high level of burden among caregivers of FTD patients (63).

Few studies have found specific motor symptoms associated with caregiver burden. One study linked poor motivation and difficulties with everyday skills to higher burden (64), while another study revealed that caregiver burden was predicted by behavioral problems and severity of limb involvement (65).

These findings highlight the support caregivers require from health care professionals and family/friends to not only manage the emotional and physical burden of caregiving (66), but also cognitive and behavioral symptoms that can greatly impact on their caregiving experience.

\section{DISCUSSION}

Assessment and management of cognitive and behavioral symptoms forms the larger goal of preservation of quality of life in both ALS patients and caregivers. Timely assessment of cognitive and behavioral symptoms has important prognostic and therapeutic implications. The presence of dysexecutive symptoms is not only likely to impact on patient and caregiver psychological well-being but also decision-making, adherence to life-sustaining interventions, and capacity to engage and benefit from non-pharmacological interventions. Additionally, cognitive and behavioral symptoms may exist before full blown motor symptoms (67) and, therefore, the ability to make informed decisions may be effected early in the disease course. While treatments for symptomatic management in ALS is often most beneficial if initiated early [e.g., (68)] and clinicians value proactive decisions (69), failure to identify cognitive and behavioral symptoms may mean that patients are not fully supported by their health care team and caregivers to undertake informed decision-making that is in accordance with their current personal philosophy and values (70). 
The provision of practical support by ALS specialists is known to facilitate adherence in ALS. Increased educational training and adaptation facilitates adherence to non-invasive ventilation (71); telemonitoring decreases emergency room visits and hospital admissions, and follow-up care between clinical visits increase adherence to clinical recommendations $(36,72)$. Support from other ALS patients through online platforms can also increase treatment adherence such as with medication adherence (73).

It is also essential to recognize the importance of caregivers in the management of ALS from an early stage, informing them about the possibility of burden, offering them health care support, and monitoring their well-being over time (74). Weisser et al. (75) showed that the needs of ALS caregivers were multiple, including practical, social, and psychological needs. A model of coping was subsequently proposed integrating resilience, burden, needs, and rewards (75). An intervention to reduce maladaptive coping strategies has also been found to improve well-being in caregivers of patients with ALS (76). Furthermore, the use of technological approaches (e.g., telemedicine) for ALS patients and their caregivers that live in remote and rural areas which have reduced access to health care services may be especially beneficial (77). Provision of training for health care professionals to help patients and caregivers during the advanced stages of the disease would also ensure that important factors such as fatigue, stress, and ethical challenges related to end-of-life care are adequaly addressed (78).

To the best of our knowledge, there are currently no evidencebased studies which examine interventions to manage the cognitive and behavioral symptoms of ALS patients, though there are a few that examine caregiver burden in response to behavioral symptoms (79). In the absence of such evidence, it is possible to extrapolate findings from intervention studies in non-ALS populations as possible non-pharmacological interventions for cognitive and behavioral symptoms in ALS. Behavioral variant FTD and cognitively impaired ALS show similar cognitive profiles, although cognitive deficits are more severe in patients with behavioral variant FTD in most domains (4). In both disorders, considerable impairment in social cognition, fluency and verbal memory is found, whereas impairment of visual memory and attention is less prominent $(3,4)$. Due to the similarity of symptoms, studies examining management of behavioral variant FTD may be relevant to ALS, though caution should be used in extrapolating their conclusions.

Environmental management has shown promise in addressing cognitive/behavioral symptoms of FTD patients (80). For example, reducing noise and stimulation, lessening clutter, or simplifying social situations can help patient's better focus on a nominated task or response $(80,81)$. Removing access to problematic stimuli or modifying public outings to reduce the opportunity for inappropriate interactions are also effective FTD-specific environmental manipulations (80, 81), which could also be implemented when working with ALS patients presenting symptoms of disinhibition or loss of social cognition.
Though the research on behavioral modification in FTD is also limited and consists mainly of case studies and reports, clinicians have typically focused on disinhibition, apathy and compulsive behaviors $(80,82)$. In a few specific cases, behavioral interventions successfully reduced behaviors that were most distressing for patients' and caregivers', improved the relationship between patients' and caregivers', and helped to prevent the patients from being institutionalized $(82,83)$. Two case reports used behavior theory techniques including reducing stimuli, introducing new non-verbal cues, and creating reward systems (82, 83). Similarly, Tailored Activities Programs have been shown to reduce agitation in behavioral variant FTD patients (83-85). Support groups for family caregivers have also proved helpful (in person and when using online live streams) and most effective when caregivers are experiencing similar behaviors and challenges with the patient $(86,87)$.

There are limitations to understanding the impact of cognitive and behavioral changes on patients with ALS and their caregivers. The majority of published studies have been completed in developed countries and thus results cannot be extrapolated to all countries. Also, many of these studies do not take into consideration the various socioeconomic variables attributable to the patient and caregivers daily experience with ALS, such as the individual's wealth or their country's health care system.

Despite the clinical necessity of an intervention to manage cognitive and behavioral symptoms, there has been a lack of research on the topic which further widens the gap between research and practice. Drawing from interventions in dementia, there is a large landscape of possible, untested interventions for cognitive and behavioral symptoms of ALS. Early and comprehensive management of cognitive and behavioral symptoms not only promotes holistic care of patients but would also further enhance caregiver's psychological wellbeing and likely to reduce the healthcare and societal burden of these symptoms due to poor intervention adherence and avoidable hospitalizations.

\section{AUTHOR CONTRIBUTIONS}

JC, SH, PL, and KD wrote the manuscript. EM edited it and had manuscript oversight.

\section{FUNDING}

JC holds a National Health and Medical Research Council of Australia Postgraduate Research Scholarship (APP1092891). $\mathrm{SH}$ holds a National Health and Medical Research Council of Australia-Dementia Research Development Fellowship. PL is funded by CONICYT/FONDAP 15150012, CONICYT/FONDECYT regular 1160940. KD is funded by MND Scotland. EM holds a grant from the Motor Neurone Disease Association UK. 


\section{REFERENCES}

1. Kiernan MC, Vucic S, Cheah BC, Turner MR, Eisen A, Hardiman O, et al. Amyotrophic lateral sclerosis. Lancet. (2011) 377:942-55. doi: 10.1016/S0140-6736(10)61156-7

2. Turner MR, Hardiman O, Benatar M, Brooks BR, Chio A, de Carvalho M, et al. Controversies and priorities in amyotrophic lateral sclerosis. Lancet Neurol. (2013) 12:310-22. doi: 10.1016/S1474-4422(13)70036-X

3. Strong MJ, Abrahams S, Goldstein LH, Woolley S, McLaughlin P, Snowden J, et al. Amyotrophic lateral sclerosis - frontotemporal spectrum disorder (ALS-FTSD): revised diagnostic criteria. Amyotr Lateral Scler Frontotemporal Degener. (2017) 18:153-74. doi: 10.1080/21678421.2016.1267768

4. Beeldman E, Raaphorst J, Klein Twennaar M, Govaarts R, Pijnenburg YAL, de Haan RJ, et al. The cognitive profile of behavioural variant FTD and its similarities with ALS: a systematic review and meta-analysis. J Neurol Neurosurg Psychiatry. (2018) 89:995-1002. doi: 10.1136/jnnp-2017-317459

5. Goldstein LH, Abrahams S. Changes in cognition and behaviour in amyotrophic lateral sclerosis: nature of impairment and implications for assessment. Lancet Neurol. (2013) 12:368-80. doi: 10.1016/S1474-4422(13)70026-7

6. Phukan J, Pender NP, Hardiman O. Cognitive impairment in amyotrophic lateral sclerosis. Lancet Neurol. (2007) 6:994-1003. doi: 10.1016/S1474-4422(07)70265-X

7. Raaphorst J, Beeldman E, De Visser M, De Haan RJ, Schmand B. A systematic review of behavioural changes in motor neuron disease. Amyotroph Lateral Scler. (2012) 13:493-501. doi: 10.3109/17482968.2012.656652

8. Raaphorst J, de Visser M, Linssen WH, de Haan RJ, Schmand B. The cognitive profile of amyotrophic lateral sclerosis: a meta-analysis. Amyotroph Lateral Scler. (2010) 11:27-37. doi: 10.3109/17482960802645008

9. Miller RG, Jackson CE, Kasarskis EJ, England JD, Forshew D, Johnston W, et al. Practice parameter update: the care of the patient with amyotrophic lateral sclerosis: multidisciplinary care, symptom management, and cognitive/behavioral impairment (an evidence-based review): report of the Quality Standards Subcommittee of the American Academy of Neurology. Neurology. (2009) 73:1227-33. doi: 10.1212/WNL.0b013e3181bc01a4

10. Rabkin J, Goetz R, Murphy JM, Factor-Litvak P, Mitsumoto H, Group ACS. Cognitive impairment, behavioral impairment, depression, and wish to die in an ALS cohort. Neurology. (2016) 87:1320-8. doi: 10.1212/WNL.0000000000003035

11. Wei Q, Zheng Z, Guo X, Ou R, Chen X, Huang R, et al. Association between depression and survival in Chinese amyotrophic lateral sclerosis patients. Neurol Sci. (2016) 37:557-63. doi: 10.1007/s10072-015-2472-y

12. Carelli L, Solca F, Faini A, Madotto F, Lafronza A, Monti A, et al. The complex interplay between depression/anxiety and executive functioning: insights from the ECAS in a large ALS population. Front Psychol. (2018) 9:450. doi: 10.3389/fpsyg.2018.00450

13. Chen D, Guo X, Zheng Z, Wei Q, Song W, Cao B, et al. Depression and anxiety in amyotrophic lateral sclerosis: correlations between the distress of patients and caregivers. Muscle Nerve. (2015) 51:353-7. doi: 10.1002/mus. 24325

14. Cui F, Zhu W, Zhou Z, Ren Y, Li Y, Li M, et al. Frequency and risk factor analysis of cognitive and anxiety-depressive disorders in patients with amyotrophic lateral sclerosis/motor neuron disease. Neuropsychiatr Dis Treat. (2015) 11:2847-54. doi: 10.2147/NDT.S90520

15. Korner S, Kollewe K, Abdulla S, Zapf A, Dengler R, Petri S. Interaction of physical function, quality of life and depression in Amyotrophic lateral sclerosis: characterization of a large patient cohort. BMC Neurol. (2015) 15:84. doi: 10.1186/s12883-015-0340-2

16. Paganoni S, McDonnell E, Schoenfeld D, Yu H, Deng J, Atassi H, Atassi N. Functional Decline is Associated with Hopelessness in Amyotrophic Lateral Sclerosis (ALS). J Neurol Neurophysiol. (2017) 8:423. doi: 10.4172/2155-9562.1000423

17. Poletti B, Solca F, Carelli L, Madotto F, Lafronza A, Faini A, et al. The validation of the italian edinburgh cognitive and behavioural ALS Screen (ECAS). Amyotr Lateral Scler Frontotemporal Degener. (2016) 17:489-98. doi: 10.1080/21678421.2016.1183679

18. Prado LGR, Bicalho ICS, Vidigal-Lopes M, Prado VGR, Gomez RS, de Souza LC, et al. Depression and anxiety in a case series of amyotrophic lateral sclerosis: frequency and association with clinical features. Einstein. (2017) 15:58-60. doi: 10.1590/s1679-45082017ao3870

19. Stephens HE, Lehman E, Raheja D, Yang C, Walsh S, Simmons Z. The role of mental health and self-efficacy in the pain experience of patients with amyotrophic lateral sclerosis. Amyotr Lateral Scler Frontotemporal Degener. (2016) 17:206-12. doi: 10.3109/21678421.2015.1131832

20. Thakore NJ, Pioro EP. Depression in ALS in a large self-reporting cohort. Neurology. (2016) 86:1031-8. doi: 10.1212/WNL.0000000000002465

21. Van Groenestijn AC, Schroder CD, Kruitwagen-Van Reenen ET, Van Den Berg LH, Visser-Meily JMA. Participation restrictions in ambulatory amyotrophic lateral sclerosis patients: physical and psychological factors. Muscle Nerve. (2017) 56:912-8. doi: 10.1002/mus.25574

22. Longinetti $\mathrm{E}$, Mariosa $\mathrm{D}$, Larsson $\mathrm{H}$, Ye $\mathrm{W}$, Ingre $\mathrm{C}$, Almqvist $\mathrm{C}$, et al. Neurodegenerative and psychiatric diseases among families with amyotrophic lateral sclerosis. Neurology. (2017) 89:578-85. doi: 10.1212/WNL.0000000000004179

23. Roos E, Mariosa D, Ingre C, Lundholm C, Wirdefeldt K, Roos PM, et al. Depression in amyotrophic lateral sclerosis. Neurology. (2016) 86:2271-7. doi: 10.1212/WNL.0000000000002671

24. Turner MR, Goldacre R, Talbot K, Goldacre MJ. Psychiatric disorders prior to amyotrophic lateral sclerosis. Ann Neurol. (2016) 80:935-8. doi: 10.1002/ana.24801

25. Caga J, Ramsey E, Hogden A, Mioshi E, Kiernan MC. A longer diagnostic interval is a risk for depression in amyotrophic lateral sclerosis. Palliat Support Care. (2015) 13:1019-24. doi: 10.1017/S1478951514000881

26. Londral A, Pinto A, Pinto S, Azevedo L, De Carvalho M. Quality of life in amyotrophic lateral sclerosis patients and caregivers: impact of assistive communication from early stages. Muscle Nerve. (2015) 52:933-41. doi: 10.1002/mus.24659

27. Lule D, Nonnenmacher S, Sorg S, Heimrath J, Hautzinger M, Meyer T, et al. Live and let die: existential decision processes in a fatal disease. $J$ Neurol. (2014) 261:518-25. doi: 10.1007/s00415-013-7229-Z

28. Maessen M, Veldink JH, Onwuteaka-Philipsen BD, Hendricks HT, Schelhaas HJ, Grupstra HF, et al. Euthanasia and physician-assisted suicide in amyotrophic lateral sclerosis: a prospective study. J Neurol. (2014) 261:1894901. doi: 10.1007/s00415-014-7424-6

29. Pagnini F. Psychological wellbeing and quality of life in amyotrophic lateral sclerosis: a review. Int J Psychol. (2013) 48:194-205. doi: 10.1080/00207594.2012.691977

30. Simmons Z. Patient-Perceived Outcomes and Quality of Life in ALS. Neurotherapeutics. (2015) 12:394-402. doi: 10.1007/s13311-0140322-x

31. Lule D, Ehlich B, Lang D, Sorg S, Heimrath J, Kubler A, et al. Quality of life in fatal disease: the flawed judgement of the social environment. J Neurol. (2013) 260:2836-43. doi: 10.1007/s00415-013-7068-y

32. Albrecht GL, Devlieger PJ. The disability paradox: high quality of life against all odds. Soc Sci Med. (1999) 48:977-88. doi: 10.1016/S0277-9536(98)00411-0

33. Radakovic R, Stephenson L, Colville S, Swingler R, Chandran S, Abrahams S. Multidimensional apathy in ALS: validation of the Dimensional Apathy Scale. J Neurol Neurosurg Psychiatry. (2016) 87:663-9. doi: 10.1136/jnnp-2015-310772

34. Santangelo G, Siciliano M, Trojano L, Femiano C, Monsurro MR, Tedeschi G, et al. Apathy in amyotrophic lateral sclerosis: insights from Dimensional Apathy Scale. Amyotroph Lateral Scler Frontotemporal Degener. (2017) 18:434-42. doi: 10.1080/21678421.2017.1313865

35. Bourke SC, Bullock RE, Williams TL, Shaw PJ, Gibson GJ. Noninvasive ventilation in ALS: indications and effect on quality of life. Neurology. (2003) 61:171-7. doi: 10.1212/01.WNL.0000076182.13137.38

36. Fullam T, Stephens HE, Felgoise SH, Blessinger JK, Walsh S, Simmons Z. Compliance with recommendations made in a multidisciplinary ALS clinic. Amyotroph Lateral Scler Frontotemporal Degener. (2015) 17:30-7. doi: 10.3109/21678421.2015.1074703

37. Giordana MT, Ferrero P, Grifoni S, Pellerino A, Naldi A, Montuschi A Dementia and cognitive impairment in amyotrophic lateral sclerosis: a review. Neurol Sci. (2011) 32:9-16. doi: 10.1007/s10072-010-0439-6

38. Irwin D, Lippa CF, Swearer JM. Cognition and amyotrophic lateral sclerosis (ALS). Am J Alzheimer's Dis Dementias. (2007) 22:300-12. doi: $10.1177 / 1533317507301613$ 
39. Witgert M, Salamone AR, Strutt AM, Jawaid A, Massman PJ, Bradshaw $M$, et al. Frontal-lobe mediated behavioral dysfunction in amyotrophic lateral sclerosis. Eur J Neurol. (2010) 17:103-10. doi: 10.1111/j.1468-1331.2009.02801.x

40. Woolley SC, Jonathan SK. Cognitive and behavioral impairment in amyotrophic lateral sclerosis. Phys Med Rehabil Clin North Am. (2008) 19:607-17, xi. doi: 10.1016/j.pmr.2008.04.002

41. Olney RK, Murphy J, Forshew D, Garwood E, Miller BL, Langmore S, et al. The effects of executive and behavioral dysfunction on the course of ALS. Neurology. (2005) 65:1774-7. doi: 10.1212/01.wnl.0000188759. $87240.8 \mathrm{~b}$

42. Clawson LL, Cudkowicz M, Krivickas L, Brooks BR, Sanjak M, Allred P, et al. Randomized controlled trial of resistance and endurance exercise in amyotrophic lateral sclerosis. Amyotroph Lateral Scler Frontotemporal Degener. (2018) 19:250-8. doi: 10.1080/21678421.2017.1404108

43. Nicholson TT, Smith SB, Siddique T, Sufit R, Ajroud-Driss S, Coleman JM 3rd, et al. Respiratory pattern and tidal volumes differ for pressure support and volume-assured pressure support in amyotrophic lateral sclerosis. Ann Am Thoracic Soc. (2017) 14:1139-46. doi: 10.1513/AnnalsATS.201605$346 \mathrm{OC}$

44. Introna A, D'Errico E, Modugno B, Scarafino A, Fraddosio A, Distaso E, et al. Adherence to riluzole in patients with amyotrophic lateral sclerosis: an observational study. Neuropsychiatr Dis Treat. (2018) 14:193-203. doi: 10.2147/NDT.S150550

45. Jacobs TL, Brown DL, Baek J, Migda EM, Funckes T, Gruis KL. Trial of early noninvasive ventilation for ALS: a pilot placebo-controlled study. Neurology. (2016) 87:1878-83. doi: 10.1212/WNL.0000000000003158

46. van Groenestijn AC, van de Port IG, Schroder CD, Post MW, Grupstra HF, Kruitwagen ET, et al. Effects of aerobic exercise therapy and cognitive behavioural therapy on functioning and quality of life in amyotrophic lateral sclerosis: protocol of the FACTS-2-ALS trial. BMC Neurol. (2011) 11:70. doi: 10.1186/1471-2377-11-70

47. Bertella E, Banfi P, Paneroni M, Grilli S, Bianchi L, Volpato E, et al. Early initiation of night-time NIV in an outpatient setting: a randomized noninferiority study in ALS patients. Eur J Phys Rehabil Med. (2017) 53:892-9. doi: 10.23736/S1973-9087.17.04511-7

48. Jackson CE, Lovitt S, Gowda N, Anderson F, Miller RG, Bradley WG, et al. Factors correlated with NPPV use in ALS. Amyotr Later Scler. (2006) 7:80-5. doi: 10.1080/14660820500504587

49. Kim SM, Park KS, Nam H, Ahn SW, Kim S, Sung JJ, et al. Capnography for assessing nocturnal hypoventilation and predicting compliance with subsequent noninvasive ventilation in patients with ALS. PLoS ONE. (2011) 6:e17893. doi: 10.1371/journal.pone.0017893

50. Pinto AC, de Carvalho M, Evangelista T, Lopes A, Sales-Luis L. Nocturnal pulse oximetry: a new approach to establish the appropriate time for noninvasive ventilation in ALS patients. Amyotr Later Scler Motor Neuron Disorders. (2003) 4:31-5. doi: 10.1080/14660820310006706

51. Atassi N, Yerramilli-Rao P, Szymonifka J, Yu H, Kearney M, Grasso D, et al. Analysis of start-up, retention, and adherence in ALS clinical trials. Neurology. (2013) 81:1350-5. doi: 10.1212/WNL.0b013e3182a823e0

52. Thomas PT, Warrier MG, Sadasivan A, Balasubramanium B, PreethishKumar V, Nashi S, et al. Caregiver burden and quality of life of patients with amyotrophic lateral sclerosis in India. Amyotroph Lateral Scler Frontotemporal Degener. 19:606-10. doi: 10.1080/21678421.2018.1482353

53. Oh J, An JW, Oh KW, Oh SI, Kim JA, Kim SH, et al. [Depression and caregiving burden in families of patients with amyotrophic lateral sclerosis]. J Korean Acad Nurs. (2015) 45:202-10. doi: 10.4040/jkan.2015. 45.2.202

54. Burke T, Elamin M, Galvin M, Hardiman O, Pender N. Caregiver burden in amyotrophic lateral sclerosis: a cross-sectional investigation of predictors. $J$ Neurol. (2015) 262:1526-32. doi: 10.1007/s00415-015-7746-Z

55. Burke T, Galvin M, Pinto-Grau M, Lonergan K, Madden C, Mays I, et al. Caregivers of patients with amyotrophic lateral sclerosis: investigating quality of life, caregiver burden, service engagement, and patient survival. J Neurol. (2017) 264:898-904. doi: 10.1007/s00415-017-8448-5

56. Burke T, Hardiman O, Pinto-Grau M, Lonergan K, Heverin M, Tobin K, et al. Longitudinal predictors of caregiver burden in amyotrophic lateral sclerosis: a population-based cohort of patient-caregiver dyads. J Neurol. (2018) 265:793-808. doi: 10.1007/s00415-018-8770-6

57. Galvin M, Corr B, Madden C, Mays I, McQuillan R, Timonen V, et al. Caregiving in ALS - a mixed methods approach to the study of Burden. BMC Palliat Care. (2016) 15:81. doi: 10.1186/s12904-016-0153-0

58. Bruletti G, Comini L, Scalvini S, Morini R, Luisa A, Paneroni M, et al. A twoyear longitudinal study on strain and needs in caregivers of advanced ALS patients. Amyotroph Lateral Scler Frontotemporal Degener .(2015) 16:187-95. doi: 10.3109/21678421.2014.974616

59. Tramonti F, Bongioanni P, Leotta R, Puppi I, Rossi B. Age, gender, kinship and caregiver burden in amyotrophic lateral sclerosis. Psychol Health Med. (2015) 20:41-6. doi: 10.1080/13548506.2014.892627

60. Cui B, Cui L, Gao J, Liu M, Li X, Liu C, et al. Cognitive impairment in chinese patients with sporadic amyotrophic lateral sclerosis. PLoS ONE. (2015) 10:e0137921. doi: 10.1371/journal.pone.0137921

61. Bock M, Duong YN, Kim A, Allen I, Murphy J, Lomen-Hoerth C. Cognitive-behavioral changes in amyotrophic lateral sclerosis: screening prevalence and impact on patients and caregivers. Amyotroph Lateral Scler Frontotemporal Degener. (2016) 17:366-73. doi: 10.3109/21678421.2016. 1165257

62. Tremolizzo L, Pellegrini A, Susani E, Lunetta C, Woolley SC, Ferrarese $\mathrm{C}$, et al. Behavioural but not cognitive impairment is a determinant of caregiver burden in amyotrophic lateral sclerosis. Eur Neurol. (2016) 75:1914. doi: 10.1159/000445110

63. Hsieh S, Leyton CE, Caga J, Flanagan E, Kaizik C, O'Connor CM, et al. The evolution of caregiver burden in frontotemporal dementia with and without amyotrophic lateral sclerosis. J Alzheimers Dis. (2016) 49:875-85. doi: 10.3233/JAD-150475

64. Andrews SC, Pavlis A, Staios M, Fisher F. Which behaviours? Identifying the most common and burdensome behaviour changes in amyotrophic lateral sclerosis. Psychol Health Med. (2017) 22:483-92. doi: 10.1080/13548506.2016.1164871

65. Watermeyer TJ, Brown RG, Sidle KC, Oliver DJ, Allen C, Karlsson J, et al. Impact of disease, cognitive and behavioural factors on caregiver outcome in amyotrophic lateral sclerosis. Amyotroph Lateral Scler Frontotemporal Degener. (2015) 16:316-23. doi: 10.3109/21678421.2015.1051990

66. Galvin M, Carney S, Corr B, Mays I, Pender N, Hardiman O. Needs of informal caregivers across the caregiving course in amyotrophic lateral sclerosis: a qualitative analysis. BMJ Open. (2018) 8:e018721. doi: 10.1136/bmjopen-2017-018721

67. Mioshi E, Caga J, Lillo P, Hsieh S, Ramsey E, Devenney E, et al. Neuropsychiatric changes precede classic motor symptoms in ALS and do not affect survival. Neurology. (2014) 82:149-55. doi: 10.1212/WNL.0000000000000023

68. Terzano C, Romani S. Early use of non invasive ventilation in patients with amyotrophic lateral sclerosis: what benefits? Eur Rev Med Pharmacol Sci. (2015) 19:4304-13.

69. Hogden A, Greenfield D, Nugus P, Kiernan MC. Engaging in patient decision-making in multidisciplinary care for amyotrophic lateral sclerosis: the views of health professionals. Patient Prefer Adherence. (2012) 6:691-701. doi: $10.2147 /$ PPA.S36759

70. Hogden A, Greenfield D, Nugus P, Kiernan MC. What are the roles of carers in decision-making for amyotrophic lateral sclerosis multidisciplinary care? Patient Prefer Adherence. (2013) 7:171-81. doi: 10.2147/PPA.S4 0783

71. Volanti P, Cibella F, Sarva M, De Cicco D, Spanevello A, Mora G, et al. Predictors of non-invasive ventilation tolerance in amyotrophic lateral sclerosis. J Neurol Sci. (2011) 303:114-8. doi: 10.1016/j.jns.2010. 12.021

72. Pinto A, Almeida JP, Pinto S, Pereira J, Oliveira AG, de Carvalho M. Home telemonitoring of non-invasive ventilation decreases healthcare utilisation in a prospective controlled trial of patients with amyotrophic lateral sclerosis. J Neurol Neurosurg Psychiatry. (2010) 81:1238-42. doi: 10.1136/jnnp.2010.206680

73. Wicks P, Mack Thorley E. Scaling PatientsLikeMe via a "Generalized Platform” for Members with Chronic Illness: web-based survey study of benefits Arising. (2018) 20:e175. doi: 10.2196/jmir.9909 
74. de Wit J, Schroder CD, El Mecky J, Beelen A, van den Berg LH, VisserMeily JMA. Support needs of caregivers of patients with amyotrophic lateral sclerosis: a qualitative study. Palliat Support Care. (2018) 5:1-7. doi: $10.1017 /$ S1478951517001213

75. Weisser FB, Bristowe K, Jackson D. Experiences of burden, needs, rewards and resilience in family caregivers of people living with motor neurone disease/amyotrophic lateral sclerosis: a secondary thematic analysis of qualitative interviews. Palliat Med. (2015) 29:737-45. doi: $10.1177 / 0269216315575851$

76. Siciliano M, Santangelo G, Trojsi F, Di Somma C, Patrone M, Femiano C, et al. Coping strategies and psychological distress in caregivers of patients with Amyotrophic Lateral Sclerosis (ALS). Amyotroph Lateral Scler Frontotemporal Degener. (2017) 18:367-77. doi: 10.1080/21678421.2017.1285316

77. Geronimo A, Wright C, Morris A, Walsh S, Snyder B, Simmons Z. Incorporation of telehealth into a multidisciplinary ALS Clinic: feasibility and acceptability. Amyotroph Lateral Scler Frontotemporal Degener. (2017) 18:555-61. doi: 10.1080/21678421.2017.1338298

78. Connolly S, Galvin M, Hardiman O. End-of-life management in patients with amyotrophic lateral sclerosis. Lancet Neurol. (2015) 14:435-42. doi: 10.1016/S1474-4422(14)70221-2

79. de Wit J, Bakker LA, van Groenestijn AC, van den Berg LH, Schroder CD, Visser-Meily JM, et al. Caregiver burden in amyotrophic lateral sclerosis: a systematic review. Palliat Med. (2018) 32:231-45. doi: 10.1177/0269216317709965

80. Barton C, Ketelle R, Merrilees J, Miller B. Non-pharmacological management of behavioral symptoms in frontotemporal and other dementias. Curr Neurol Neurosci Rep. (2016) 16:14. doi: 10.1007/s11910-015-0618-1

81. Merrilees J. A model for management of behavioral symptoms in frontotemporal lobar degeneration. Alzheimer Dis Assoc Disord. (2007) 21:S64-9. doi: 10.1097/WAD.0b013e31815bf774

82. Narumoto J, Miya H, Shibata K, Nakamae T, Okamura A, Matsuoka T, et al. Challenging behavior of patients with frontal dysfunction managed successfully with behavioral intervention. Psychogeriatrics. (2009) 9:147-50. doi: 10.1111/j.1479-8301.2009.00279.x
83. O'Connor CM, Clemson L, Brodaty H, Jeon YH, Mioshi E, Gitlin LN Use of the Tailored Activities Program to reduce neuropsychiatric behaviors in dementia: an Australian protocol for a randomized trial to evaluate its effectiveness. Int Psychogeriatr. (2014) 26:857-69. doi: $10.1017 /$ S1041610214000040

84. Gitlin LN, Winter L, Dennis MP, Hodgson N, Hauck WW. Targeting and managing behavioral symptoms in individuals with dementia: a randomized trial of a nonpharmacological intervention. J Am Geriatr Soc. (2010) 58:146574. doi: 10.1111/j.1532-5415.2010.02971.x

85. O'Connor CM, Clemson L, Brodaty H, Gitlin LN, Piguet O, Mioshi E. Enhancing caregivers' understanding of dementia and tailoring activities in frontotemporal dementia: two case studies. Disabil Rehabil. (2016) 38:704-14. doi: 10.3109/09638288.2015.1055375

86. Dowling GA, Merrilees J, Mastick J, Chang VY, Hubbard E, Moskowitz JT. Life enhancing activities for family caregivers of people with frontotemporal dementia. Alzheimer Dis Assoc Disord. (2014) 28:175-81. doi: 10.1097/WAD.0b013e3182a6b905

87. O'Connell ME, Crossley M, Cammer A, Morgan D, Allingham W, Cheavins B, et al. Development and evaluation of a telehealth videoconferenced support group for rural spouses of individuals diagnosed with atypical earlyonset dementias. Dementia. (2014) 13:382-95. doi: 10.1177/14713012124 74143

Conflict of Interest Statement: The authors declare that the research was conducted in the absence of any commercial or financial relationships that could be construed as a potential conflict of interest.

Copyright (c) 2019 Caga, Hsieh, Lillo, Dudley and Mioshi. This is an open-access article distributed under the terms of the Creative Commons Attribution License (CC $B Y)$. The use, distribution or reproduction in other forums is permitted, provided the original author(s) and the copyright owner(s) are credited and that the original publication in this journal is cited, in accordance with accepted academic practice. No use, distribution or reproduction is permitted which does not comply with these terms. 